Check for updates

Cite this: RSC Adv., 2020, 10, 22881

Received 9th February 2020

Accepted 6th June 2020

DOI: $10.1039 / d 0 r a 01260 b$

rsc.li/rsc-advances

\section{Cu-based metal-organic framework HKUST-1 as effective catalyst for highly sensitive determination of ascorbic acid}

\author{
Tianyang Shen, ${ }^{\mathrm{b}}$ Tianchen Liu, ${ }^{\mathrm{C}}$ Hanqi Mo, ${ }^{\mathrm{d}}$ Zichen Yuan, ${ }^{\mathrm{c}}$ Feng Cui, ${ }^{\mathrm{a}}$ Yixiang $\mathrm{Jin}^{\mathrm{b}}$ \\ and Xiaojun Chen (D)*a
}

In this work, a Cu-based nanosheet metal-organic framework (MOF), HKUST-1, was synthesised using a solvent method at room temperature. Its morphology, structure and composition were characterised by scanning electron microscopy (SEM), transmission electron microscopy (TEM), atomic force microscopy (AFM), powder X-ray diffraction (XRD), Fourier transform infrared (FTIR), Raman spectroscopy, nitrogen adsorption and desorption isotherms, energy dispersive $X$-ray spectroscopy (EDS) and elemental analysis (EA). This material was then loaded onto the surface of an indium tin oxide (ITO) electrode to catalyse the electrochemical oxidation of ascorbic acid (AA). An equal-electron-equalproton reaction was deduced from the $\mathrm{pH}$ investigation, and a diffusion-controlled process was reinforced by the dynamics study. Under optimal conditions, the oxidation peak current at $+0.02 \mathrm{~V}$ displayed a linear relationship with the concentration of AA within the ranges of $0.01-25$ and $25-$ $265 \mathrm{mM}$, respectively. The limit of detection (LOD) was $3 \mu \mathrm{M}$ at $\mathrm{S} / \mathrm{N}$ of 3 . The superb response could be ascribed to the porous nanosheet structure of HKUST-1, which enhanced both the effective surface area and the electron transfer ability significantly. Moreover, the novel AA sensor demonstrated good reproducibility, favourable stability and high sensitivity towards glucose, uric acid (UA), dopamine (DA) and several amino acids. It was also successfully applied to the real sample testing of various AAcontaining tablets.

\section{Introduction}

Ascorbic acid (AA), which is also known as vitamin C, is a polyhydroxy compound with a similar structure to glucose. ${ }^{\mathbf{1}}$ It is capable of being reduced, ${ }^{2,3}$ and thus is widely used as a natural antioxidant in food, ${ }^{4}$ juice, ${ }^{5}$ medicine ${ }^{3}$ and cosmetics. ${ }^{6}$ It is also an important water-soluble vitamin, which exists extensively as a highly active species participating in the metabolic processes of many creatures, ${ }^{7}$ fresh fruit and vegetables. ${ }^{5}$ Recently, due to the crucial functions in free radical scavenging, ${ }^{2-4}$ cell development and therapeutic areas, such as wound healing, preventing cancer and enhancing immunity, ${ }^{\mathbf{8}}$ AA has continuously attracted the public's interest. It was reported that an AA shortage could lead to the symptoms of scurvy, ${ }^{9}$ however, exaggerated amounts could induce stomach convulsions. ${ }^{\mathbf{1 0}}$ Therefore, the determination of AA concentration is of great use, which could be considered as an important physiological

${ }^{a}$ College of Chemistry and Molecular Engineering, Nanjing Tech University, Nanjing 211800, People's Republic of China. E-mail: chenxj@njtech.edu.cn

${ }^{b}$ College of Overseas Education, Nanjing Tech University, Nanjing 211800, People's Republic of China

${ }^{c}$ Nanjing Foreign Language School, Nanjing 210018, People's Republic of China

${ }^{d}$ Nanjing No. 1 Middle School, Nanjing 210001, People's Republic of China indicator for anti-aging. ${ }^{11-13}$ Additionally, because AA is in a millimole or even smaller scale, particularly in human bodies, novel facile and rapid methods contributing to selective and sensitive detection are required. This is exactly significant not only for monitoring human metabolism, but also for the supervision of food, drugs and dietary supplement. ${ }^{\mathbf{1 4}}$

Nowadays, diverse methods have been developed to improve the detection of AA, including ultra- and high-performance liquid chromatography (UPLC or HPLC), ${ }^{15}$ capillary electrophoresis, ${ }^{\mathbf{1 6}}$ fluorescence spectroscopy ${ }^{\mathbf{1 7}}$ and UV-Vis spectroscopy. ${ }^{18}$ Beyond these, electrochemical techniques are often applied, which are easy to implement and not expensive. ${ }^{19} \mathrm{With}$ modified electrode surface, the electrochemical response is promoted enormously, and the lower limit of detection (LOD) and wider linear range are accessed. ${ }^{20}$ Nevertheless, the sensitivity and reproducibility usually tend to be the issue because of interference from other biological molecules like dopamine (DA) and uric acid (UA), leading to the challenge of employment in food, drug or real sample analysis. ${ }^{20}$

Recently, many nanomaterials, such as graphene, carbon nanotubes (CNTs) ${ }^{21}$ and nanoparticles (NPs), ${ }^{22}$ have been developed and applied into electrochemical areas. Metalorganic frameworks (MOFs) are novel functional materials composed of repeated spatial or planar patterns of metal ions 
coordinated to organic ligands through covalent bonds. They have attracted increasing attention owing to the critical role in the field of molecular adsorption, ${ }^{23}$ carbon capture, ${ }^{24}$ compound separation, ${ }^{25}$ supercapacitors, ${ }^{26}$ efficient sensing ${ }^{27}$ and catalysis ${ }^{28,29}$ due to adjustable porous structures and superhigh specific areas. In electrochemical analysis, design and synthesis of different types of MOFs has become an appealing domain to study. It is reported that metal-organic frameworks are well electrochemically active to the oxidation of some small molecules such as glucose, ${ }^{30}$ nitrite, ${ }^{31}$ ethanol, ${ }^{32}$ hydrazine ${ }^{33}$ and dihydroxybenzene isomers, ${ }^{34}$ and the redox process of $\mathrm{NADH}^{35}$ and $\mathrm{H}_{2} \mathrm{O}_{2} \cdot{ }^{30,36,37}$ However, MOFs are rare as electrochemical sensors compared to others, because organic coordinates are normally bad conductors and only the metal sites are conductive. ${ }^{37,38}$ Hence, it is challenging to prepare highly conductive electrochemical sensors based on MOFs.

To the best of our knowledge, none study has been reported so far on determining the concentration of AA using MOFsmodified electrodes. In this work, the prevalent HKUST-1 framework (also known as MOF-199 or Cu-BTC) was assembled at room temperature and loaded on the indium tin oxide (ITO) electrodes to investigate the capability of electrochemical oxidation of AA. Both the metallic $\mathrm{Cu}$ ion centre and the layered structure of HKUST-1 enhanced the electron transfer greatly, improving the catalytic current dramatically. The reaction dynamic was studied to learn the kinetic parameters and the mechanism of the process. The repeatability, stability and antiinterference ability of the proposed AA sensor were also evaluated. Eventually, the application potential of the novel sensor was evidenced by testing AA content in several commercial healthcare tablets as real samples. The current research provides a new perspective for chemical sensor construction based on MOFs platform.

\section{Experimental}

\subsection{Chemicals}

Copper(II) acetate monohydrate $\left(\mathrm{Cu}\left(\mathrm{CH}_{3} \mathrm{COO}\right)_{2} \cdot \mathrm{H}_{2} \mathrm{O}\right), 1,3,5-$ benzenetricarboxylic acid $\left(\mathrm{H}_{3} \mathrm{BTC}\right)$, ethanol, acetone, cyclohexane, triethylamine, dimethylformamide (DMF), phosphoric acid $\left(\mathrm{H}_{3} \mathrm{PO}_{4}\right)$, monosodium phosphate $\left(\mathrm{NaH}_{2} \mathrm{PO}_{4}\right)$, disodium phosphate $\left(\mathrm{Na}_{2} \mathrm{HPO}_{4}\right)$, potassium chloride $(\mathrm{KCl})$, magnesium chloride $\left(\mathrm{MgCl}_{2}\right)$, potassium ferrocyanide $\left(\mathrm{K}_{4}\left[\mathrm{Fe}(\mathrm{CN})_{6}\right]\right)$, potassium ferricyanide $\left(\mathrm{K}_{3}\left[\mathrm{Fe}(\mathrm{CN})_{6}\right]\right)$, AA, uric acid (UA), dopamine (DA), glucose, glycine (Gly), L-methionine (L-Met), L-glutamic acid (L-Glu), tryptophan (Trp), L-cysteine (L-Cys), cystine (Cys) and tyrosine (Tyr). Real AA samples, including vitamin C honeysuckle pills, vitamin $\mathrm{C}$ buccal tablets for children and multi-vitamin effervescent tablets, were purchased from market. The water used in this work was double distilled water (DDW). The phosphate buffered solution (PBS) was prepared as $0.1 \mathrm{M}$ at $\mathrm{pH} 6.5$ by dissolving $2.1373 \mathrm{~g} \mathrm{NaH} \mathrm{PO}_{4}$ and $2.2560 \mathrm{~g}$ $\mathrm{Na}_{2} \mathrm{HPO}_{4}$ in $200 \mathrm{~mL}$ water, and was acidified to the desired values by adding $0.2 \mathrm{M}$ of $\mathrm{H}_{3} \mathrm{PO}_{4}$. All chemicals were of analytical grade and used as received.

\subsection{Apparatus}

The morphology of HKUST-1 was studied by scanning electron microscopy (SEM, Hitachi S4800) and transmission electron microscopy (TEM, JEOL JEM-200CX). The thickness was measured by atomic force microscopy (AFM, Bruker, Dimension Icon). The elemental composition analysis was investigated by energy dispersive X-ray spectroscopy (EDS Falcon 60S, EDAX Inc.) and CHNS/O elemental analyzer (Elementar Vario EL Cube). To characterise the crystal structure of HKUST-1, the power X-ray diffraction (XRD) pattern was performed by Philips X'Pert X-ray diffractometer with $\mathrm{Cu} \mathrm{K} \alpha$ X-ray source. The bonding and functional groups were recorded using Fourier-
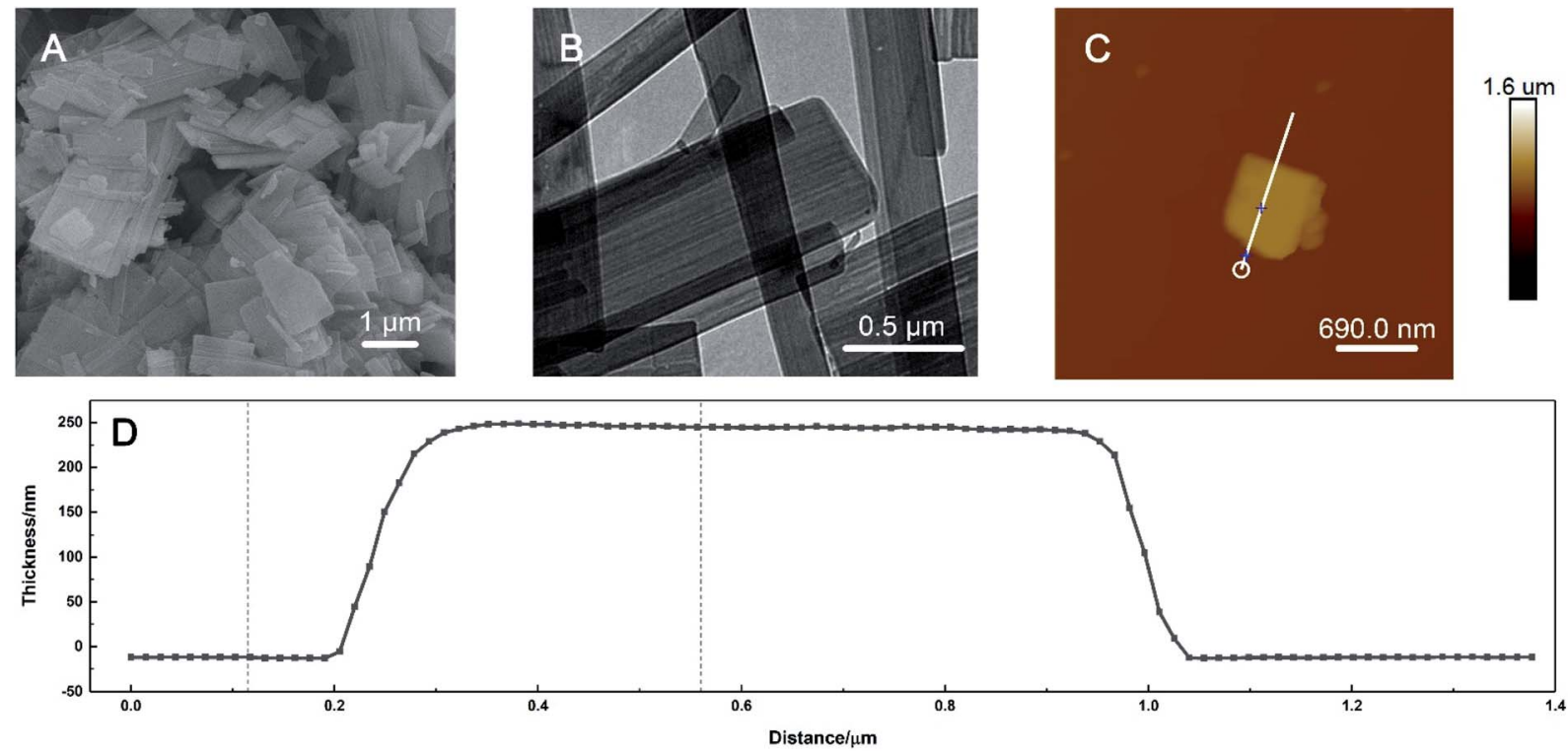

Fig. 1 (A) SEM, (B) TEM, (C) AFM images and (D) the corresponding thickness profile of the prepared HKUST-1. 
transform infrared spectra (Nicolet is 10 FT-IR spectrophotometer, Thermo Fisher Scientific Inc., USA) and Raman spectra (DXR2 Raman Microscope, Thermo Fisher Scientific Inc., USA). The nitrogen sorption and desorption isotherms were measured with a Micromeritics ASAP 2020 analyser. The specific surface area of HKUST-1 was determined using the standard Brunauer-Emmett-Teller (BET) method, while the pore size distribution was calculated by the Barrett-Joyner-Halenda (BJH) method.

All the cyclic voltammetry (CV) and differential pulse voltammetry (DPV) measurements were implemented on the electrochemical workstation (CHI650E, Shanghai Chenhua Instrument Co., China). A typical three-electrode system was applied in $0.1 \mathrm{M}$ PBS at room temperature, which was composed of a HKUST-1/ITO working electrode, an $\mathrm{Ag} / \mathrm{AgCl}$ reference electrode and a platinum wire auxiliary electrode.

\subsection{Preparation of HKUST-1}

HKUST-1 was synthesised at room temperature as previous reports. ${ }^{38,39} 0.60 \mathrm{~g}$ of $\mathrm{Cu}\left(\mathrm{CH}_{3} \mathrm{COO}\right)_{2} \cdot \mathrm{H}_{2} \mathrm{O}$ was dissolved in $50 \mathrm{~mL}$ of water and $0.42 \mathrm{~g}$ of $\mathrm{H}_{3}$ BTC was dissolved in $50 \mathrm{~mL}$ of ethanol, respectively. After they were completely mixed, another mixture of $10 \mathrm{~mL}$ of cyclohexane and $0.85 \mathrm{~mL}$ of triethylamine was added dropwise. Then, blue solids formed and precipitated afterwards. The reaction was allowed to stand for $24 \mathrm{~h}$ before the solids were centrifuged and washed with DDW and ethanol, sequentially. The obtained product was dried in vacuum for $12 \mathrm{~h}$ at $50{ }^{\circ} \mathrm{C}$.

\subsection{Fabrication of HKUST-1 modified ITO electrode}

Typically, $10 \mathrm{mg}$ of HKUST-1 was dispersed into $5 \mathrm{~mL}$ of DMF to form a $2.0 \mathrm{mg} \mathrm{mL} \mathrm{mL}^{-1}$ stable suspension. All ITO electrodes were washed by acetone followed by ethanol and DDW before use. After drying with nitrogen, $7.0 \mu \mathrm{L}$ of the suspension was dropped onto ITO surface with the controlled geometric diameter of $1.0 \mathrm{~mm}$ and then dried in air for use..$^{40}$

\section{Results and discussion}

\subsection{Morphology characterisation of HKUST-1}

The morphology of the prepared HKUST- 1 was characterised by SEM, TEM and AFM. As shown in Fig. 1A, the SEM image exhibited that the shape of the material was irregular-layered sheets with smooth surfaces. The length of the sheets extended to the micrometre scale, as seen in the TEM image in Fig. 1B. The large space between the sheets increased the specific area greatly, which would improve the electron-transfer efficiency when HKUST-1 nanosheets were loaded on the ITO surface. AFM was utilized to measure the average thickness of the sheets. For a specific single layer shown in Fig. 1C, the prepared HKUST-1 sheet has a planar and homogeneous morphology with the thickness of about $254 \mathrm{~nm}$ (Fig. 1D).

\subsection{Structure and composition of HKUST-1}

The chemical formula was speculated by EDS analysis in Fig. 2A. It was obvious that the molar ratio of the elements $\mathrm{C}, \mathrm{O}$ and $\mathrm{Cu}$ in the prepared HKUST-1 was $53.38: 36.98: 9.64$, which were
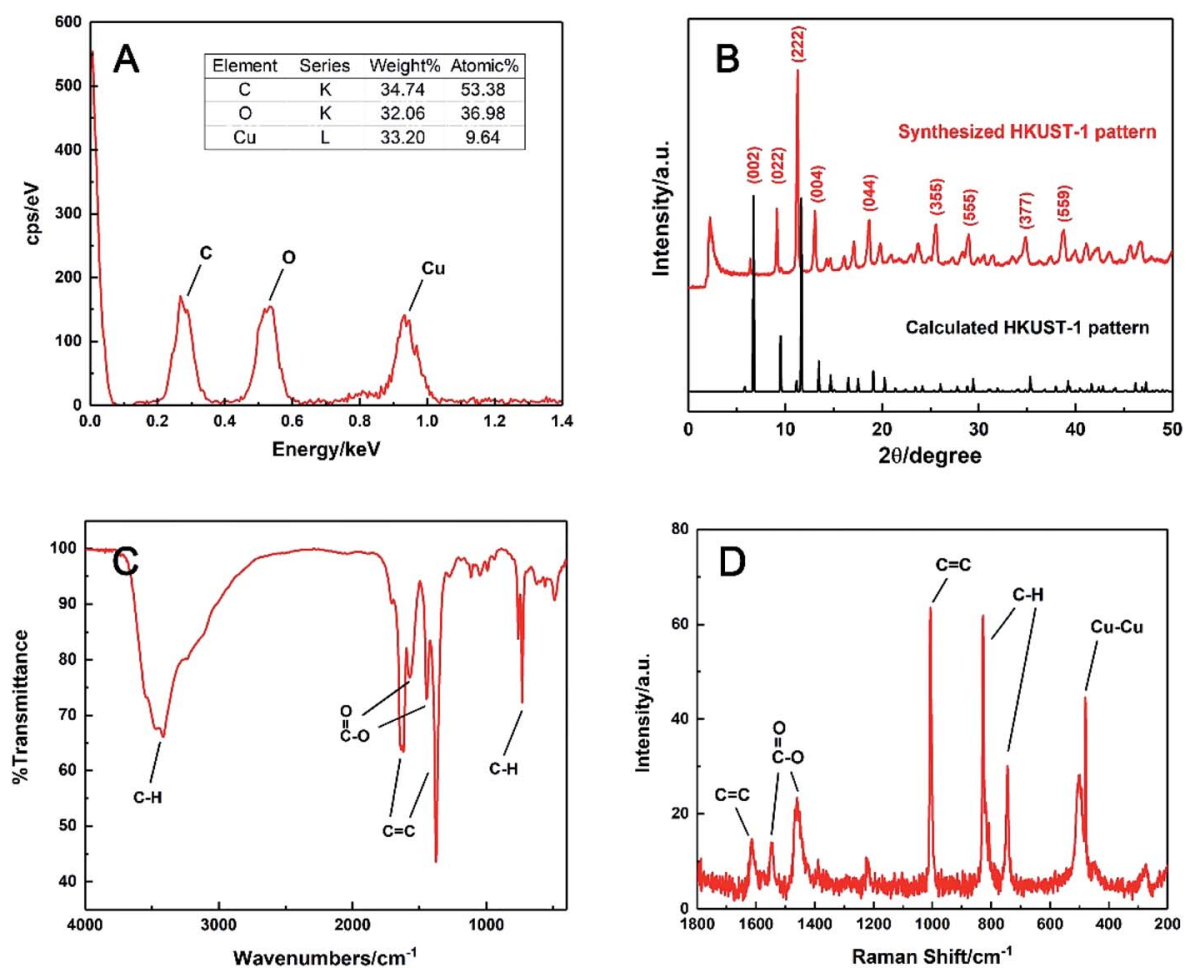

Fig. 2 (A) EDS spectrum, (B) experimental XRD pattern (red line) and the simulated curve (black line), (C) FTIR and (D) Raman spectra of the synthesised HKUST-1. 
about $6: 4: 1$. This suggested that this MOF had a formula of $\mathrm{Cu}_{3}\left(\mathrm{C}_{9} \mathrm{H}_{3} \mathrm{O}_{6}\right)_{2}$, meaning that every three $\mathrm{Cu}$ (II) could coordinate with two BTC linkers on average during precipitation. This was supported by elemental analysis as well, and it gave the exact mass percentages of $\mathrm{C}, \mathrm{H}$ and $\mathrm{O}$ in the sample are $32.77 \%$, $1.04 \%$ and $32.54 \%$, which is close to the molar ratio of $3: 1: 2$ and consistent with the formula reported before. ${ }^{38}$

The powder XRD pattern of the synthesised material was compared with the simulated one in Crystal Diffract 6.7 version. ${ }^{41,42}$ As shown in Fig. $2 \mathrm{~B}$, the strong peaks at $2 \theta$ of 6.38 , $9.14,11.26$ and $13.08^{\circ}$ were identical to the simulated ones, corresponding to the regular (002), (022), (222) and (004) planes of HKUST-1, respectively. Other weak peaks at $2 \theta$ of 18.66, 25.58, $28.94,34.78$ and $38.78^{\circ}$ also matched well with the planes of (044), (355), (555), (377) and (559), respectively. The result confirmed that the prepared HKUST-1 possessed a similar structure to the reported data. ${ }^{\mathbf{4 2}}$

Moreover, the main functional groups of HKUST-1 were characterised via FTIR and Raman spectroscopy. In Fig. 2C, the $\mathrm{C}-\mathrm{H}\left(3400 \mathrm{~cm}^{-1}\right)$ and the $\mathrm{C}=\mathrm{C}$ stretching of benzene ring (1619 and $1375 \mathrm{~cm}^{-1}$ ), the asymmetric and symmetric vibration modes of $\mathrm{C}=\mathrm{O}\left(1571\right.$ and $\left.1446 \mathrm{~cm}^{-1}\right)$ and the $\mathrm{C}-\mathrm{H}$ bending
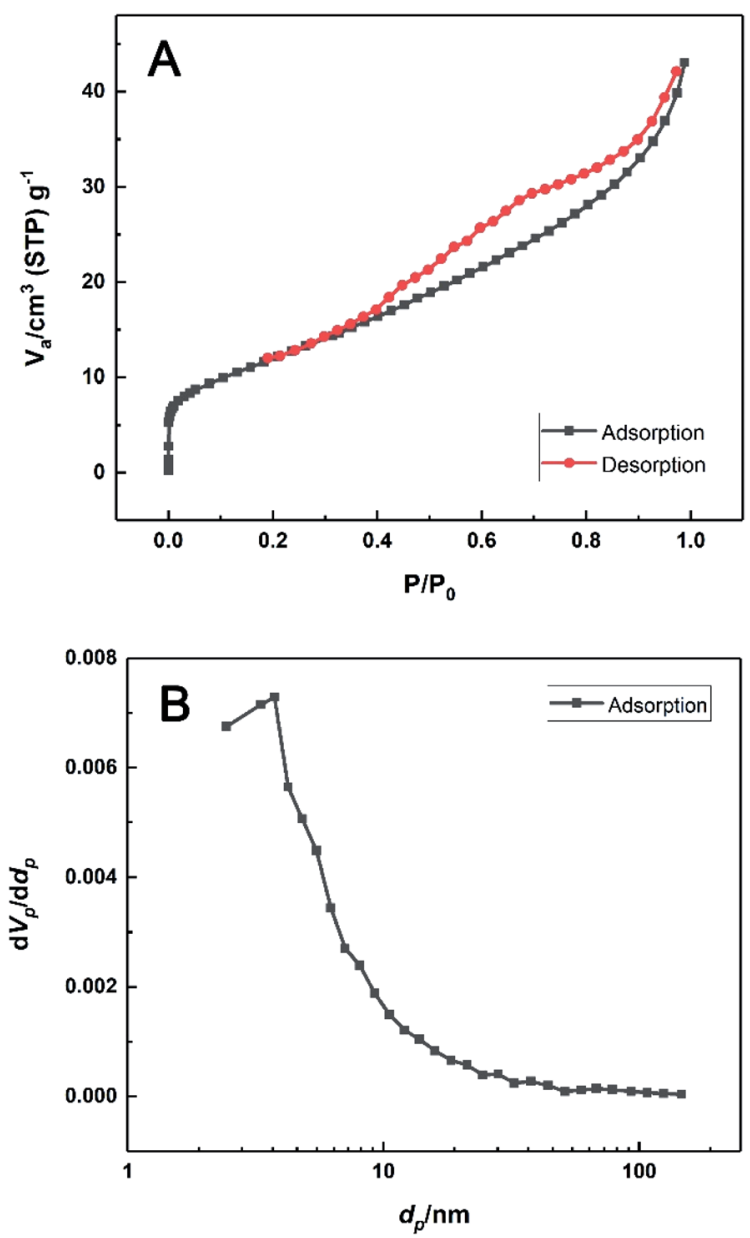

Fig. 3 (A) $\mathrm{N}_{2}$ adsorption-desorption isotherms and (B) the $\mathrm{BJH}$ desorption pore size distribution of the prepared HKUST-1.

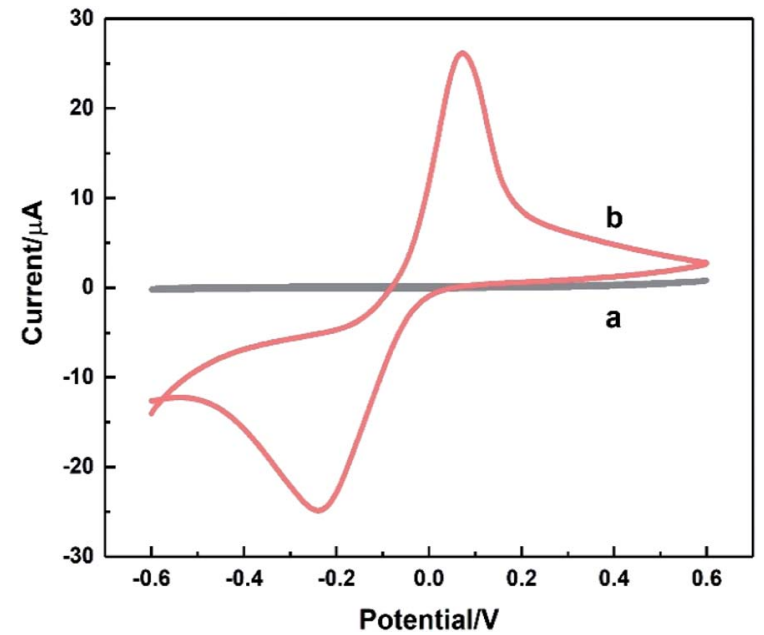

Fig. 4 CV curves recorded on bare ITO (a) and HKUST-1/ITO (b) in $0.1 \mathrm{M} \mathrm{pH} 3.63 \mathrm{PBS}$ at the scan rate of $100 \mathrm{mV} \mathrm{s}^{-1}$.

(731 $\mathrm{cm}^{-1}$ ) were clearly observed. Besides the organic fragments, the $\mathrm{Cu}-\mathrm{Cu}$ vibration band was observed at $480 \mathrm{~cm}^{-1}$ from the Raman spectrum in Fig. 2D, indicating homoatomic metal bonding. All these characteristic peaks were matched well with those of HKUST-1 described in earlier work, ${ }^{38}$ which also confirmed the formation of HKUST-1 in this work.

In addition, the structure of the nanosheets was found stable in the growth, assembly and precipitation process at room temperature. And the morphology remained unchanged even after prolonged centrifugal separation and ultrasonic oscillation.

Fig. 3 displays the nitrogen adsorption-desorption isotherms of the material at $77 \mathrm{~K}$. Clearly, the monolayer coverage was completed within the vicinity of the inflexion point in the low relative pressure region. Afterwards, the isotherm indicated infinite multilayer adsorption and no saturation limit was observed. This behaviour was typically an IUPAC Type II isotherm and the multilayer adsorption was attributed to the nanosheets structure of HKUST-1. The desorption isotherm presented a hysteresis loop of $\mathrm{H} 4$ type in the high-pressure region. ${ }^{43}$ Moreover, the BET specific surface area was determined as $45 \mathrm{~m}^{2} \mathrm{~g}^{-1}$, with the mean pore diameter of $5.92 \mathrm{~nm}$, which was might resulted from sheet stacking or capillary condensation in the mesopores.

\subsection{Electrochemical behaviour of HKUST-1}

The electrochemical behaviour of HKUST-1/ITO was studied using CV before it was implemented on the detection of AA. In Fig. 4, the CV responses on ITO (curve a) and HKUST-1/ITO (curve b) in $0.1 \mathrm{M} \mathrm{pH} \mathrm{3.63} \mathrm{PBS} \mathrm{were} \mathrm{recorded} \mathrm{at} \mathrm{a} \mathrm{scan} \mathrm{rate} \mathrm{of}$ $100 \mathrm{mV} \mathrm{s}^{-1}$. There were no obvious peaks observed on bare ITO due to non-electroactive material existed electrode surface. However, a pair of obvious oxidation-reduction peaks was observed on HKUST-1/ITO, corresponding to the conversion between $\mathrm{Cu}(\mathrm{II})$ and $\mathrm{Cu}(\mathrm{I}) .{ }^{44}$ Both the metallic $\mathrm{Cu}$ ion centre in HKUST-1 and the space between nanosheets enhanced the electron transfer greatly, improving the current dramatically. 

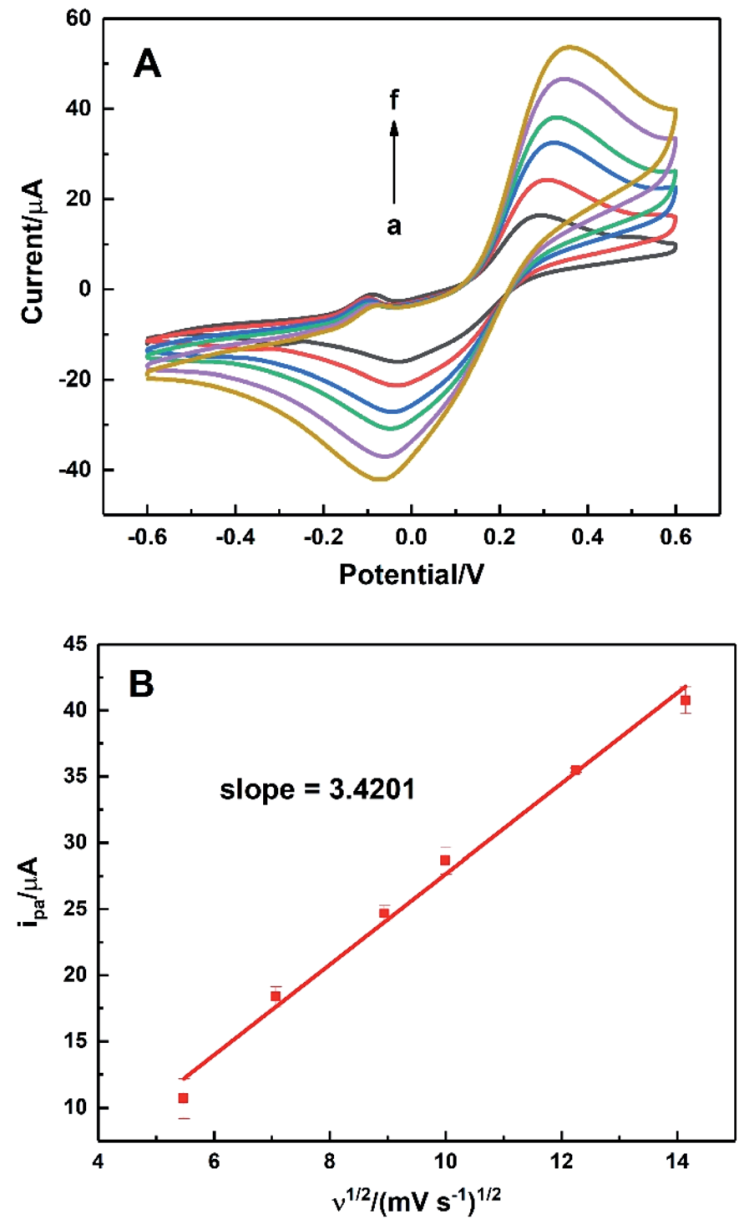

Fig. 5 (A) CVs of HKUST-1/ITO in $2.5 \mathrm{mM} \mathrm{K}_{3} \mathrm{Fe}(\mathrm{CN})_{6} / \mathrm{K}_{4} \mathrm{Fe}(\mathrm{CN})_{6}$ solution containing $0.1 \mathrm{M} \mathrm{KCl}$ without $\mathrm{AA}$ at different scan rate of 30 , $50,80,100,150$ and $200 \mathrm{mV} \mathrm{s}^{-1}$ (from a to f), (B) the linear plot of $i_{\mathrm{pa}} v \mathrm{~s}$. $\nu^{1 / 2}$.

\subsection{Determination of effective surface area}

To evaluate the effective surface area (ESA) of the HKUST-1/ITO electrode, CV analysis was applied in the redox system of $\mathrm{Fe}(\mathrm{CN})_{6}{ }^{3-} / \mathrm{Fe}(\mathrm{CN})_{6}{ }^{4-}$. Fig. 5A illustrated the CVs of HKUST-1/ ITO in $2.5 \mathrm{mM} \mathrm{K}_{3} \mathrm{Fe}(\mathrm{CN})_{6}$ solution containing $0.1 \mathrm{M} \mathrm{KCl}$ at various scan rates. Then, the diffusion-controlled kinetics was also deduced from the linear relationship between oxidation peak currents $i_{\mathrm{pa}}$ and square root of scan rates $\nu^{1 / 2}$, as shown in Fig. 5B, with the regression equation of $i_{\mathrm{pa}} / \mu \mathrm{A}=3.4201 \nu^{1 / 2} /(\mathrm{mV}$ $\left.\mathrm{S}^{-1}\right)^{1 / 2}-6.5569\left(R^{2}=0.9913\right)$. Herein, the ESA value of the modified electrode could be calculated by Randles-Sevcik equation: ${ }^{45,46}$

$$
\begin{aligned}
i_{\mathrm{p}} & =0.4463 n F A C\left(\frac{n F \nu D}{R T}\right)^{1 / 2} \\
& =2.69 \times 10^{5} n^{3 / 2} A C D^{1 / 2} \nu^{1 / 2}\left(\text { at } 25^{\circ} \mathrm{C}\right)
\end{aligned}
$$

where $i_{\mathrm{p}}(\mathrm{A})$ is the peak current in an oxidation or reduction process, $n=1$ is the total number of electrons exchanged in $\mathrm{Fe}(\mathrm{CN})_{6}{ }^{3-} / \mathrm{Fe}(\mathrm{CN})_{6}{ }^{4-}$ redox reaction, $A\left(\mathrm{~cm}^{2}\right)$ is the effective surface area, $C\left(\mathrm{~mol} \mathrm{~cm}^{-3}\right)$ is the concentration of the molecule

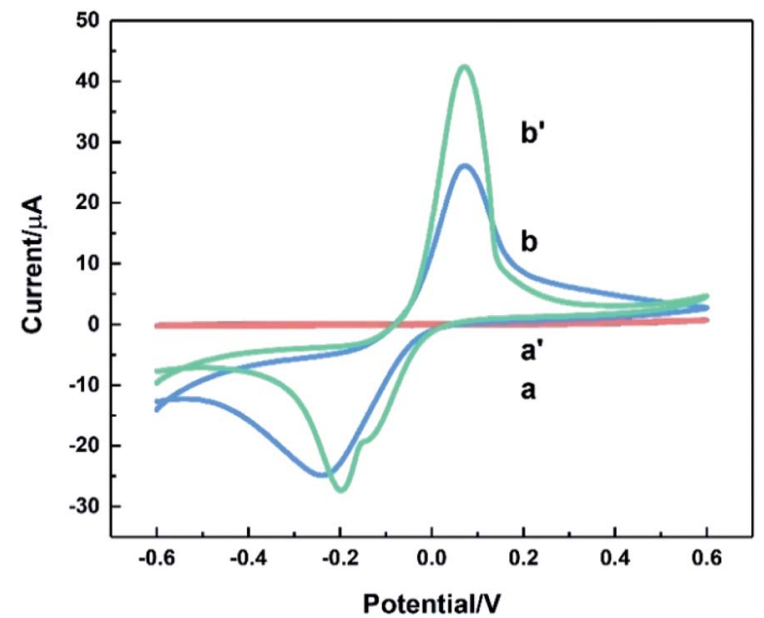

Fig. 6 CVs of bare ITO ( $a$ and $\left.a^{\prime}\right)$ and HKUST-1/ITO ( $b$ and $\left.b^{\prime}\right)$ in $0.1 \mathrm{M}$ $\mathrm{pH} 3.63$ PBS solution without ( $a$ and $b$ ) and with $200 \mathrm{mM} \mathrm{AA}\left(a^{\prime}\right.$ and $b^{\prime}$ ) at the scan rate of $100 \mathrm{mV} \mathrm{s}^{-1}$.

$\mathrm{Fe}(\mathrm{CN})_{6}{ }^{3-}$ in the solution $(2.5 \mathrm{mM}), D\left(\mathrm{~cm}^{2} \mathrm{~s}^{-1}\right)$ is the diffusion coefficient of $\mathrm{Fe}(\mathrm{CN})_{6}{ }^{3-}\left(6.5 \times 10^{-6} \mathrm{~cm}^{2} \mathrm{~s}^{-1}\right)$ and $\nu\left(\mathrm{V} \mathrm{s}^{-1}\right)$ is the scan rate. In this case, the slope was 3.4201 , hence the ESA of HKUST-1/ITO was determined as $0.06308 \mathrm{~cm}^{2}$, which was about 8.03 times of that of bare ITO. This indicated that the HKUST-1 modification enhanced the catalytic ability by providing more electrochemical active sites.

\subsection{Electrocatalytic oxidation of AA on HKUST-1/ITO}

Fig. 6 depicted CV curves on bare ITO (a and $\mathrm{a}^{\prime}$ ) and HKUST-1/ ITO ( $b$ and $b^{\prime}$ ) in $0.1 \mathrm{M} \mathrm{pH} \mathrm{3.63} \mathrm{PBS} \mathrm{in} \mathrm{the} \mathrm{absence} \mathrm{(} a$ and $b$ ) and presence $\left(\mathrm{a}^{\prime}\right.$ and $\left.\mathrm{b}^{\prime}\right)$ of $200 \mathrm{mM}$ AA at the scan rate of $100 \mathrm{mV} \mathrm{s}^{-1}$. Comparison of curve a and $\mathrm{a}^{\prime}$ revealed no evidence for the catalytic effect of bare ITO on the AA oxidation. However, from curve $\mathrm{b}$ and $\mathrm{b}^{\prime}$, the oxidation peak current increased about twofold towards AA, illustrating AA could be catalytically oxidised by HKUST-1. Furthermore, a possible mechanism focusing on the interaction between AA and HKUST-1 was investigated. AA was oxidised by $\mathrm{Cu}(\mathrm{II})$, and meanwhile $\mathrm{Cu}$ (II) was reduced to $\mathrm{Cu}(\mathrm{I})$. That is to say, HKUST-1 catalysed the oxidation of AA, and the oxidation peak current of HKUST-1 was enhanced. The overall reaction equations were as follows: ${ }^{47,48}$

$$
\begin{aligned}
2 \mathrm{Cu}(\mathrm{II})+\mathrm{C}_{6} \mathrm{H}_{8} \mathrm{O}_{6} & \rightarrow 2 \mathrm{Cu}(\mathrm{I})+2 \mathrm{H}^{+}+\mathrm{C}_{6} \mathrm{H}_{6} \mathrm{O}_{6} \\
2 \mathrm{Cu}(\mathrm{I}) & \rightarrow 2 \mathrm{Cu}(\mathrm{II})+2 \mathrm{e}^{-}
\end{aligned}
$$

\subsection{Effect of solution $\mathbf{p H}$}

Fig. 7 shows the behaviour of HKUST-1/ITO in $0.1 \mathrm{M}$ PBS solution at different $\mathrm{pH}$ values ranging from 3.00 to 6.31 in the presence of $1 \mathrm{mM}$ AA via $\mathrm{CV}$ technique. It could be seen from Fig. 7A, the oxidation peak moved negatively as $\mathrm{pH}$ increased, illustrating it was a proton-participated electrochemical reaction. It was found that the oxidation potential of AA was inversely proportional to $\mathrm{pH}$ value (Fig. 7B), with a fitting 

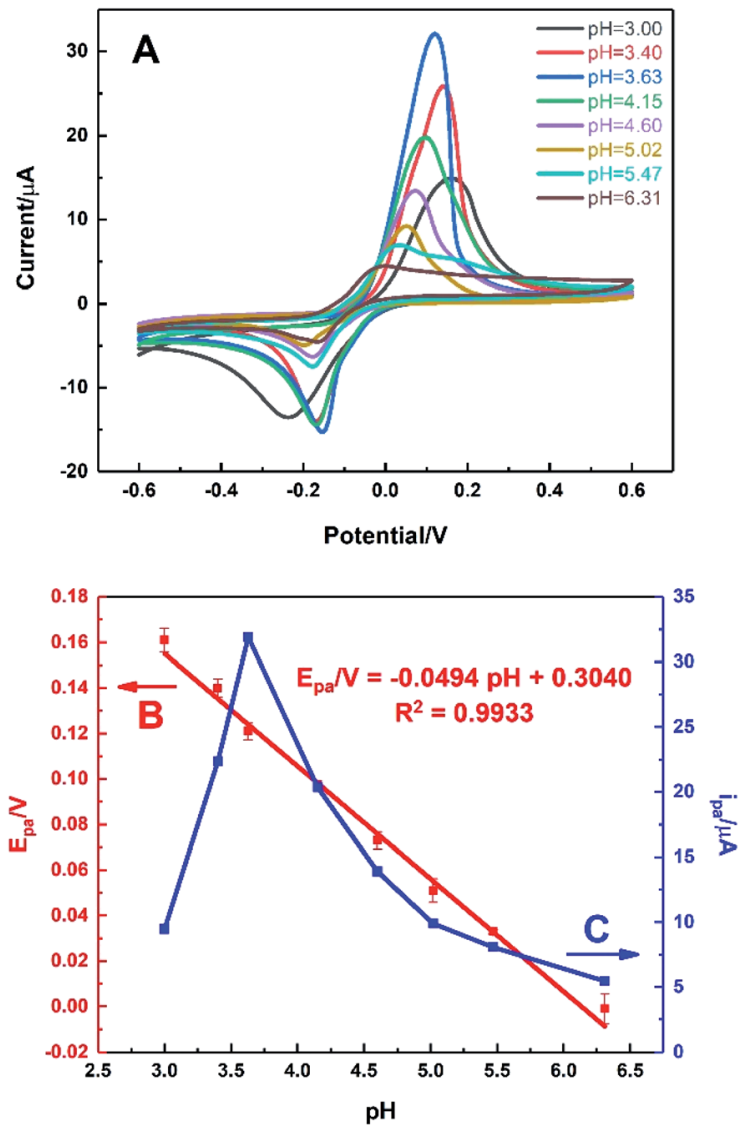

Fig. 7 (A) CVs of HKUST-1/ITO in 0.1 M PBS solution under different $\mathrm{pH}$ values ranging from 3.00 to 6.31 for $1 \mathrm{mM}$ AA at the scan rate of $100 \mathrm{mV} \mathrm{s}^{-1}$. Plots of (B) oxidation potential and (C) oxidation current $v \mathrm{~s}$. $\mathrm{pH}$ from $\mathrm{CVs}$.

equation of $E_{\mathrm{pa}} / \mathrm{V}=-0.0494 \mathrm{pH}+0.3040\left(R^{2}=0.9933\right)$. It meant that AA could be oxidised at not only acidic but also neutral circumstances, indicating the further physiological application of the sensor. Moreover, the slope of $-0.0494 \mathrm{~V}$ per $\mathrm{pH}$ unit was close to the theoretical value of $-0.0592 \mathrm{~V}$ per $\mathrm{pH}$ unit in Nernst equation, illustrating the electron transfer process was accompanied by equal number of protons transferred. In Fig. 7C, it could be seen that the oxidation current of AA increased sharply from $\mathrm{pH} 3.00$ to 3.63 , achieving the highest value. Then, the current decreased rapidly as $\mathrm{pH}$ rose, which might be owing to the proton-participated reaction. Thus, the optimal pH value was chosen as 3.63 in this work to ensure the high sensitivity.

\subsection{Effect of modification amount of HKUST-1}

The influence of the modification amount of HKUST-1 was studied using DPV, and the result was shown in Fig. 8. The modification amount did have great impacts on the oxidation peak current. It was found that the oxidation current of AA increased sharply when the modification amount of $2 \mathrm{mg}$ $\mathrm{mL}^{-1}$ HKUST-1 suspension increased from 1.5 to $7.0 \mu \mathrm{L}$. The possible reason might be that the large amount of catalyst brought enhanced catalytic ability. However, the current decreased as the modification amount more than $7.0 \mu \mathrm{L}$,

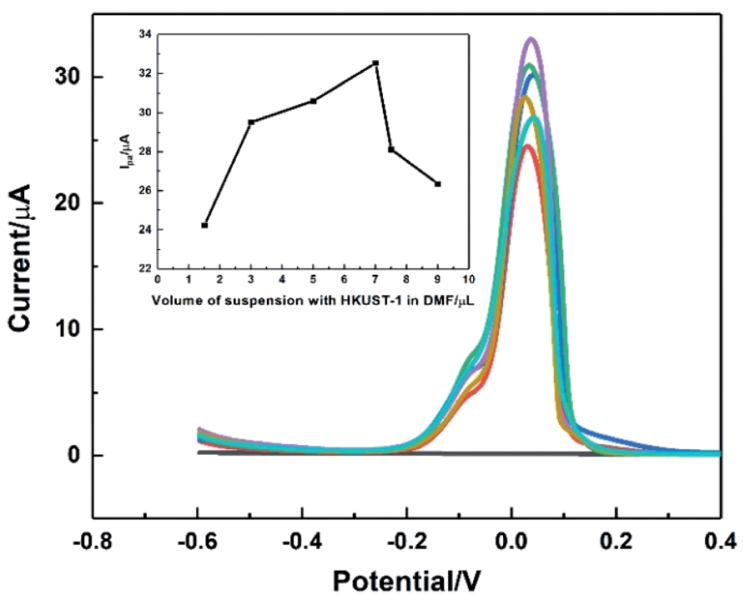

Fig. 8 DPVs recorded on HKUST-1/ITO with different modification volume of $2 \mathrm{mg} \mathrm{mL}^{-1}$ HKUST-1 suspension from 1.5 to $9.0 \mu \mathrm{L}$, in $0.1 \mathrm{M}$ $\mathrm{pH} 3.63$ PBS solution upon $1 \mathrm{mM} \mathrm{AA}$ at the scan rate of $100 \mathrm{mV} \mathrm{s}^{-1}$. Inset was the plot of $I_{\text {pa }} v s$. modification volume.

attributing to the fact that the thicker modification layer was easy to crack and fall off from the electrode surface. Therefore, $7.0 \mu \mathrm{L}$ suspension of HKUST-1 was selected as the optimal modification amount in this work.

\subsection{Effect of scan rates on dynamics of AA oxidation}

The effect of the scan rate on the electrocatalytic oxidation of AA was investigated by CVs of HKUST-1/ITO in $0.1 \mathrm{M}$ pH 3.63 PBS solution containing $1 \mathrm{mM}$ AA within the range of $30-200 \mathrm{mV}$ $\mathrm{s}^{-1}$. As illustrated in Fig. 9A, the oxidation potential shifted positively and the reduction one shifted negatively, suggesting an irreversible electrochemical process. Meanwhile, both the oxidation and reduction peak currents increased as the scan rate increased. The relationships between the anodic and cathodic current and $\nu^{1 / 2}$, expressed in Fig. 9B, were $i_{\mathrm{pa}} / \mu \mathrm{A}=$ $0.7003 \nu^{1 / 2} /\left(\mathrm{mV} \mathrm{s}^{-1}\right)^{1 / 2}+23.7727\left(R^{2}=0.9089\right)$ and $i_{\mathrm{pc}} / \mu \mathrm{A}=$ $-1.4796 \nu^{1 / 2} /\left(\mathrm{mV} \mathrm{s}^{-1}\right)^{1 / 2}-0.7818\left(R^{2}=0.9987\right)$, indicating a diffusion-controlled electrode process.

Fig. 9C showed the linear equations of the potential versus the logarithm of scan rate as $E_{\mathrm{pa}} / \mathrm{V}=0.0458 \log \nu /\left(\mathrm{mV} \mathrm{s}^{-1}\right)+$ $0.0279\left(R^{2}=0.9918\right)$ and $E_{\mathrm{pc}} / \mathrm{V}=-0.0811 \log \nu /\left(\mathrm{mV} \mathrm{s}^{-1}\right)+$ $0.0081\left(R^{2}=0.9941\right)$, respectively. A plot of logarithmic current $v s$. potential, known as a Tafel plot, is one of the useful approaches to kinetic parameters. Generally, it takes the form of

$$
\text { Slope }=\frac{\mathrm{d} \log i}{\mathrm{~d} E_{\mathrm{p}}}=\frac{\alpha_{\mathrm{a}} n_{\alpha} F}{2.303 R T} .
$$

Herein, for the irreversible and diffusion-controlled system, the relationship of peak potential shifts towards scan rate could be deduced as the following equations: ${ }^{46,49}$

$$
\left\{\begin{array}{c}
\frac{\mathrm{d} E_{\mathrm{pa}}}{\mathrm{d} \log \nu}=\frac{2.303 R T}{2 \alpha_{\mathrm{a}} n_{\alpha} F} \\
\frac{\mathrm{d} E_{\mathrm{pc}}}{\mathrm{d} \log \nu}=-\frac{2.303 R T}{2 \alpha_{\mathrm{c}} n_{\alpha} F} \\
\alpha_{\mathrm{a}}+\alpha_{\mathrm{c}}=1
\end{array}\right.
$$



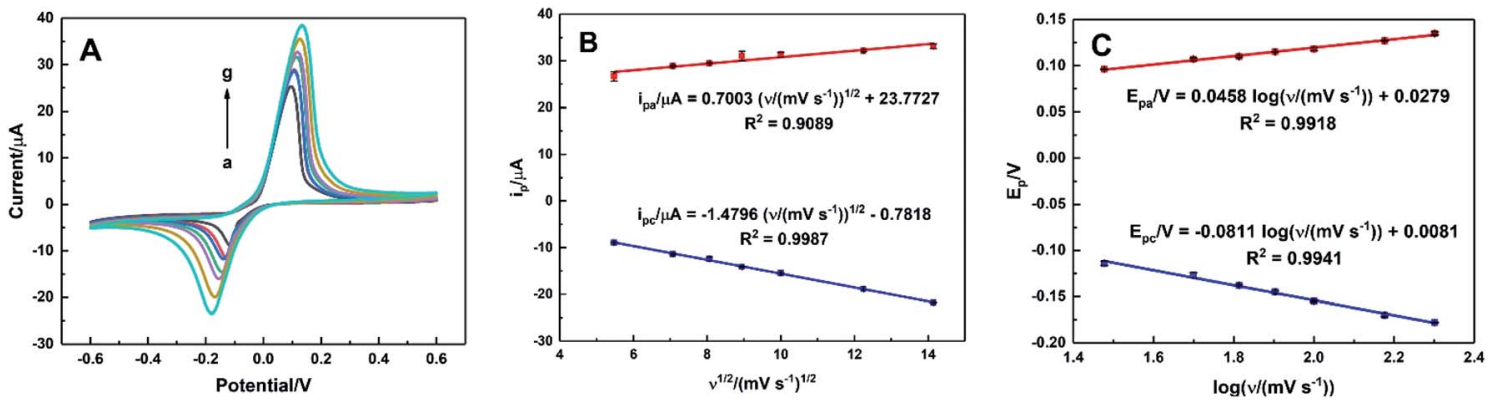

Fig. 9 (A) CVs of HKUST-1/ITO in $0.1 \mathrm{M} \mathrm{pH} 3.63$ PBS solution containing $1 \mathrm{mM} \mathrm{AA}$ at different scan rate of 30, 50, 65, 80, 100, 150 and 200 mV s${ }^{-1}$ (from a to g), (B) the linear plots of $i_{\mathrm{pa}}$ and $i_{\mathrm{pc}} v s . \nu^{1 / 2}$, and (C) the linear plots of $E_{\mathrm{pa}}$ and $E_{\mathrm{pc}} v s . \log \nu$.

where $\alpha_{\mathrm{a}}\left(\alpha_{\mathrm{c}}\right)$ is the anodic (cathodic) charge transfer coefficient and $n_{\alpha}$ is the number of electrons transferred in the ratelimiting step. Then the dynamics-relating parameters could be calculated from the slopes of the plots as $\alpha_{\mathrm{a}}=0.64, \alpha_{\mathrm{c}}=0.36$ and $n_{\alpha}=1.01$, confirming the irreversible process and proving the rate of the oxidation was determined by the single electron transfer. Considering the process underwent an equal-electronequal-proton pathway, a feasible mechanism of AA oxidation was proposed in Scheme $1 .^{50,51}$

Moreover, with the dynamics-relating parameters, the diffusion coefficient of AA could be deduced from the modified Randles-Sevcik equation for irreversible processes: ${ }^{46,52}$

$$
\begin{aligned}
i_{\mathrm{pa}} & =0.4961 n F A C\left(\frac{\alpha_{\mathrm{a}} n_{\alpha} F \nu D}{R T}\right)^{1 / 2} \\
& =2.99 \times 10^{5} n\left(\alpha_{\mathrm{a}} n_{\alpha}\right)^{1 / 2} A C D^{1 / 2} \nu^{1 / 2}\left(\text { at } 25^{\circ} \mathrm{C}\right)
\end{aligned}
$$

where $n=2$ is the total number of electrons exchanged in AA oxidation, $A=0.06308 \mathrm{~cm}^{2}$ is the effective surface area calculated before, and all the various parameters are with the same meanings and in the same units as mentioned above. According to the slope of Fig. 9B, the diffusion coefficient was estimated to be $5.33 \times 10^{-7}$ $\mathrm{cm}^{2} \mathrm{~s}^{-1}$, which corresponded to the value reported previously. ${ }^{53,54}$

\subsection{Electrochemical detection of AA}

Under the optimal conditions, the electrocatalytic responses of AA with different concentrations on HKUST-1/ITO were determined using DPV technique. As shown in Fig. 10A, the oxidation current increased when AA was added successively from 0.01 to $265 \mathrm{mM}$, while the peak potential kept around $+0.02 \mathrm{~V}$. The linear range of $\Delta i_{\mathrm{pa}} v s . C_{\mathrm{AA}}$ was composed of two parts (Fig. 10B). Here, $\Delta i$ was the difference between $i_{\mathrm{p}}$ and $i_{0}$, corresponding to the current responses with and without AA in solution, respectively.
One linear part was at a lower concentration range of 0.01$25 \mathrm{mM}$, where the current grew rapidly and the regression equation was $\Delta i / \mu \mathrm{A}=0.5098 C_{\mathrm{AA}} / \mathrm{mM}+2.6901\left(R^{2}=0.9949, n=\right.$ $6)$. The other linear part was at a higher concentration range of 25-265 mM, but the current increased in a smaller slope than before, with the linear relationship was $\Delta i / \mu \mathrm{A}=0.1444 C_{\mathrm{AA}} / \mathrm{mM}+$ $11.3245\left(R^{2}=0.9967, n=6\right)$. The sensitivity in the higher concentration range was about $28 \%$ of that in the lower concentration range, implying the catalytic rate became decreased in this situation. Furthermore, the detection limit was estimated as $3 \mu \mathrm{M}$ according to $\mathrm{S} / \mathrm{N}=3$. The sensing performance of the proposed AA sensor was also compared with those in previously reported works, as listed in Table 1 . It could be seen that our sensor revealed a wider linear range and a lower detection limit, which might since the high ESA of HKUST-1 modification provided more active sites available for electrocatalysis and the nanosheet framework structure of HKUST-1 accelerated the electron transfer between AA and electrode surface. ${ }^{19,47,55-62}$

\subsection{Repeatability, stability and selectivity of the sensor}

The repeatability was assessed using one working electrode for 15 continuous measurements towards $1.0 \mathrm{mM} \mathrm{AA}$ in $0.1 \mathrm{M} \mathrm{pH}$ 3.63 PBS solution at the scan rate of $100 \mathrm{mV} \mathrm{s}^{-1}$. The relative standard deviation (RSD) of the tested data was $2.18 \%$, showing favourable repeatability. Additionally, the short-time and longtime stability of the sensor were tested within a period of 7 and 21 days, respectively after its preparation. During this time, the modified electrodes were stored in $0.1 \mathrm{mM} \mathrm{pH} 3.63 \mathrm{PBS}$ solution. Only $2.17 \%$ and $6.91 \%$ of the current responses were found to decrease, respectively, thus indicating good stability of the sensor. Both the good repeatability and stability were attributed to the stable structure of HKUST-1 modification. In addition, it is also found that the prepared HKUST-1 is still<smiles>O=C1O[C@H]([C@H](O)CO)C(O)=C1O</smiles>

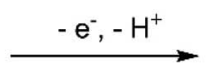

Ascorbic Acid $\mathrm{H}_{2} \mathrm{~A}$<smiles>O=C1O[C@H]([C@H](O)CO)C(O)=C1O</smiles>

$\mathrm{HA}^{\circ}$

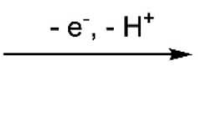

DHA

Scheme 1 A feasible mechanism of ascorbic acid oxidation. 

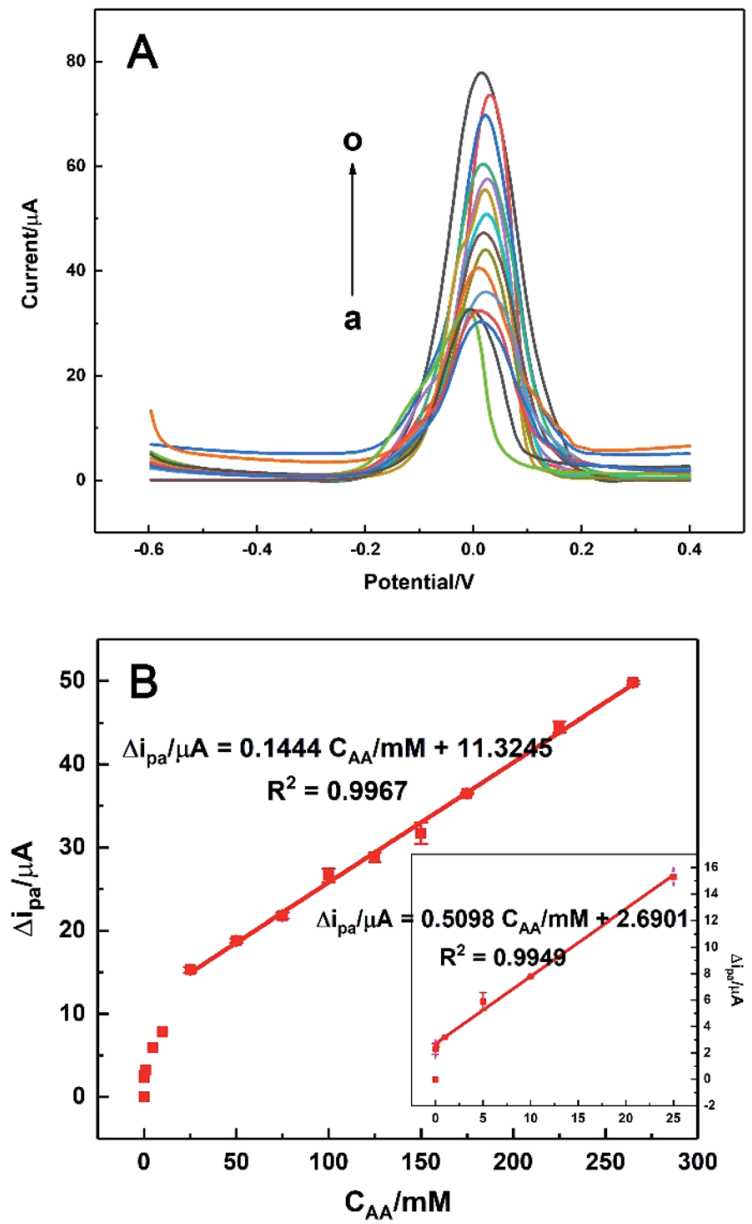

Fig. 10 (A) DPVs of HKUST-1/ITO in $0.1 \mathrm{M} \mathrm{pH} 3.63$ PBS solution with different concentrations of $A A$ at scan rate of $100 \mathrm{mV} \mathrm{s}^{-1}: 0,0.01,0.1,1$, $5,10,25,50,75,100,125,150,175,225$ and $265 \mathrm{mM}$ (from a to o). (B) The calibration curve of $\Delta i_{\mathrm{pa}}$ vs. $C_{\mathrm{AA}}$ at high concentrations and lower concentrations (inset), respectively.

stable towards acidic circumstance, which is consistent with the previous research. ${ }^{63}$

The selectivity plays an essential role in the detection of real samples and a common way was utilised to investigate the selectivity of the sensor. Ten different interfering substances,

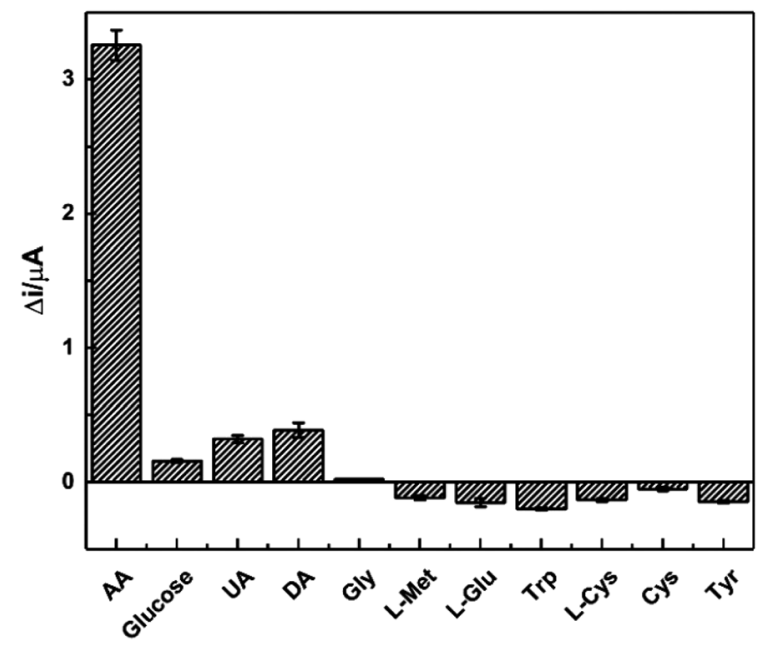

Fig. 11 Plot of $\Delta i$ responses towards $1.0 \mathrm{mM}$ of $\mathrm{AA}$ and ten interfering substances of glucose, UA, DA, Gly, L-Met, L-Glu, Trp, L-Cys, Cys and Tyr.

including glucose, DA, UA, and amino acids, etc., were examined at the concentration of $1.0 \mathrm{mM}$ in PBS solution, and the results were shown in Fig. 11. The current responses from glucose, UA and DA were less than $10 \%$ of that from AA, and most of the amino acids just reduced the current slightly. This certifies the high selectivity of the AA sensor, which forms the basis for further practical application.

\subsection{Analytical application on real samples}

In order to evaluate the practical performance of the novel AA sensor with HKUST-1/ITO, the proposed method was employed to detect the AA content in various healthcare tablets purchased from market. The tablets were dissolved in $\mathrm{pH}$ 6.5 PBS first, and the $\mathrm{pH}$ value of the solution was adjusted to 3.63 by adding $0.2 \mathrm{M} \mathrm{H}_{3} \mathrm{PO}_{4}$ after filtrating the insolubilities. The results were listed in Table 2. All of them were examined in $0.1 \mathrm{M} \mathrm{pH} 3.63$ PBS solution at room temperature and repeated for three times, the obtained relative error (RE) values compared with the nominal values outside the commodity packages were all lower

Table 1 Comparison of the proposed AA sensor performance with those in previous works

\begin{tabular}{llll}
\hline AA sensor & Linear range/mM & Detection limit/ $\mu \mathrm{M}$ & Ref. \\
\hline $\mathrm{Cu}_{4}(\mathrm{OH})_{6} \mathrm{SO}_{4} / \mathrm{ITO}$ & $0.017-6$ & 6.4 & 47 \\
Pre-anodised CPE & $0.01-1.5$ & 0.31 & 19 \\
$\mathrm{AuNPs@MoS} / \mathrm{GCE}$ & $0.05-100$ & 50 & 55 \\
$\mathrm{GEF} / \mathrm{CFE}$ & $0.07-2.31$ & 73.52 & 56 \\
$\mathrm{ZnO}-\mathrm{Cu}_{x} \mathrm{O}-\mathrm{PPy} / \mathrm{GCE}$ & $0.2-1$ & 25.0 & 57 \\
$\mathrm{rGO}-\mathrm{CNT} / \mathrm{ITO}$ & $0.01-0.2$ & 5.31 & 58 \\
$\mathrm{Pd} @ \mathrm{Au} / \mathrm{rGO} / \mathrm{GCE}$ & $0.05-2.86$ & 24.88 & 59 \\
$\mathrm{AuNPS} / \mathrm{PDDA} / \mathrm{GNS} / \mathrm{GCE}$ & $0.6-4.2$ & 80 & 60 \\
$\mathrm{HNP}-\mathrm{PtTi} / \mathrm{GCE}$ & $0.2-1$ & 24.2 & 61 \\
PrGO/PB/GCE & $0.283-2.33$ & 34.7 & 62 \\
$\mathrm{HKUST}-1 / \mathrm{ITO}$ & $0.01-25$ and $25-265$ & 3 & This work
\end{tabular}


Table 2 Determination of AA in real tablets

\begin{tabular}{llll}
\hline Sample & Sample concentration/mM & Measured concentration/mM & RE \\
\hline Vitamin C pill & 11.24 & 11.37 & $+1.15 \%$ \\
Vitamin C buccal tablet & 13.63 & 13.56 & $-0.49 \%$ \\
Multi-vitamin effervescent tablet & 42.58 & 43.68 & $+2.57 \%$
\end{tabular}

than $\pm 3 \%$, indicating accurate detection in real sensing system and verifying the excellent selectivity of the sensor.

\section{Conclusions}

In summary, a typical type of Cu-based nanosheet-structure MOFs (HKUST-1) nanomaterials was prepared in this work, and based on which a novel electrochemical sensor for AA detection was fabricated. HKUST-1 exhibited good electrocatalysis to AA, since its porous structure promoted the electron transfer significantly. Besides, a two-step mechanism was proposed to explain the oxidation pathway of AA, where the equal number of electrons and protons were involved. Under the optimal experimental conditions, the AA sensor exhibited a wide linear range of 0.01-25 and $25-265 \mathrm{mM}$, a low limit of detection of $3 \mu \mathrm{M}$ at $\mathrm{S} / \mathrm{N}=3$, good reproducibility, favourable stability and high sensitivity. Furthermore, it was successfully applied in the real sample testing, indicating potential practical value.

\section{Conflicts of interest}

There are no conflicts to declare.

\section{Acknowledgements}

This work was financially supported by the National Key Research and Development Program (2017YFC1600604), National Natural Science Foundation of China (No. 21575064), the Six Talent Peaks Project in Jiangsu Province (2016-SWYY022), and the Qinlan Project of Jiangsu Education Department (2016).

\section{Notes and references}

1 J. Hvoslef, Acta Crystallogr., Sect. B: Struct. Crystallogr. Cryst. Chem., 1968, 24, 1431-1440.

2 N. A. Akram, F. Shafiq and M. Ashraf, Front. Plant Sci., 2017, 8, 613.

3 M. G. Traber and J. F. Stevens, Free Radical Biol. Med., 2011, 51, 1000-1013.

4 E. Choe and D. B. Min, Compr. Rev. Food Sci. Food Saf., 2009, 8, 345-358.

5 H. Wang, G. H. Cao and R. L. Prior, J. Agric. Food Chem., 1996, 44, 701-705.

6 M. Gallarate, M. E. Carlotti, M. Trotta and S. Bovo, Int. J. Pharm., 1999, 188, 233-241.

7 D. R. Gallie, J. Exp. Bot., 2013, 64, 433-443.
8 B. A. Eipper, R. E. Mains and C. C. Glembotski, Proc. Natl. Acad. Sci. U. S. A., 1983, 80, 5144-5148.

9 S. J. Padayatty, A. Katz, Y. Wang, P. Eck, O. Kwon, J.-H. Lee, S. Chen, C. Corpe, A. Dutta, S. K. Dutta and M. Levine, J. Am. Coll. Nutr., 2003, 22, 18-35.

10 M. Sonmez, G. Turk and A. Yuce, Theriogenology, 2005, 63, 2063-2072.

11 G. C. de Menezes, M. Tavares-Dias, E. A. Ono, J. I. de Andrade, E. M. Brasil, R. Roubach, E. C. Urbinati, J. L. Marcon and E. G. Affonso, Comp. Biochem. Physiol., Part A: Mol. Integr. Physiol., 2006, 145, 274-279.

12 S. Gueguen, P. Pirollet, P. Leroy, J.-C. Guilland, J. Arnaud, F. Paille, G. Siest, S. Visvikis, S. Hercberg and B. Herbeth, J. Am. Coll. Nutr., 2003, 22, 303-310.

13 S. E. Gariballa and A. J. Sinclair, Br. J. Nutr., 2007, 80, 7-23. 14 J. Ping, J. Wu, Y. Wang and Y. Ying, Biosens. Bioelectron., 2012, 34, 70-76.

15 I. Klimczak and A. Gliszczynska-Swiglo, Food Chem., 2015, 175, 100-105.

16 T. Wu, Y. Guan and J. Ye, Food Chem., 2007, 100, 1573-1579.

17 M. Zheng, Z. Xie, D. Qu, D. Li, P. Du, X. Jing and Z. Sun, ACS Appl. Mater. Interfaces, 2013, 5, 13242-13247.

18 B. Shyla and G. Nagendrappa, Food Chem., 2013, 138, 20362042.

19 J. Wang, J. e. Huo, J. Li, E. Shangguan and Q. Li, Anal. Methods, 2013, 5, 4119-4125.

20 M. Sajid, M. K. Nazal, M. Mansha, A. Alsharaa, S. M. S. Jillani and C. Basheer, Trends Anal. Chem., 2016, 76, 15-29.

21 S. He, Y. Yu, Z. Chen, Q. Shi and L. Zhang, Anal. Lett., 2014, 48, 248-258.

22 E. Molaakbari, A. Mostafavi and H. Beitollahi, Sens. Actuators, B, 2015, 208, 195-203.

23 Q. Yang, Y. Wang, J. Wang, F. Liu, N. Hu, H. Pei, W. Yang, Z. Li, Y. Suo and J. Wang, Food Chem., 2018, 254, 241-248.

24 M. Bui, C. S. Adjiman, A. Bardow, E. J. Anthony, A. Boston, S. Brown, P. S. Fennell, S. Fuss, A. Galindo, L. A. Hackett, J. P. Hallett, H. J. Herzog, G. Jackson, J. Kemper, S. Krevor, G. C. Maitland, M. Matuszewski, I. S. Metcalfe, C. Petit, G. Puxty, J. Reimer, D. M. Reiner, E. S. Rubin, S. A. Scott, N. Shah, B. Smit, J. P. M. Trusler, P. Webley, J. Wilcox and N. Mac Dowell, Energy Environ. Sci., 2018, 11, 1062-1176.

25 J. R. Li, R. J. Kuppler and H. C. Zhou, Chem. Soc. Rev., 2009, 38, 1477-1504.

26 M. Liu, F. Zhao, D. Zhu, H. Duan, Y. Lv, L. Li and L. Gan, Mater. Chem. Phys., 2018, 211, 234-241.

27 H. R. Fu, Y. Zhao, Z. Zhou, X. G. Yang and L. F. Ma, Dalton Trans., 2018, 47, 3725-3732. 
28 J. Lee, O. K. Farha, J. Roberts, K. A. Scheidt, S. T. Nguyen and J. T. Hupp, Chem. Soc. Rev., 2009, 38, 1450-1459.

29 J. Duan, S. Chen and C. Zhao, Nat. Commun., 2017, 8, 15341.

30 D. Zhang, J. Zhang, R. Zhang, H. Shi, Y. Guo, X. Guo, S. Li and B. Yuan, Talanta, 2015, 144, 1176-1181.

31 B. Yuan, J. Zhang, R. Zhang, H. Shi, N. Wang, J. Li, F. Ma and D. Zhang, Sens. Actuators, B, 2016, 222, 632-637.

32 L. Yang, S. Kinoshita, T. Yamada, S. Kanda, H. Kitagawa, M. Tokunaga, T. Ishimoto, T. Ogura, R. Nagumo, A. Miyamoto and M. Koyama, Angew. Chem., Int. Ed., 2010, 49, 5348-5351.

33 H. Hosseini, H. Ahmar, A. Dehghani, A. Bagheri, A. R. Fakhari and M. M. Amini, Electrochim. Acta, 2013, 88, 301-309.

34 Y. Yang, Q. Wang, W. Qiu, H. Guo and F. Gao, J. Phys. Chem. C, 2016, 120, 9794-9803.

35 Y. Zhang, X. Bo, C. Luhana, H. Wang, M. Li and L. Guo, Chem. Commun., 2013, 49, 6885-6887.

36 H. Dai, W. Lu, X. Zuo, Q. Zhu, C. Pan, X. Niu, J. Liu, H. Chen and X. Chen, Biosens. Bioelectron., 2017, 95, 131-137.

37 L. Wang, H. Yang, J. He, Y. Zhang, J. Yu and Y. Song, Electrochim. Acta, 2016, 213, 691-697.

38 L. Ji, Q. Cheng, K. Wu and X. Yang, Sens. Actuators, B, 2016, 231, 12-17.

39 Y. V. Kaneti, J. Tang, R. R. Salunkhe, X. Jiang, A. Yu, K. C. Wu and Y. Yamauchi, Adv. Mater., 2017, 29, 1604898.

40 H. Hosseini, H. Ahmar, A. Dehghani, A. Bagheri, A. Tadjarodi and A. R. Fakhari, Biosens. Bioelectron., 2013, 42, 426-429.

41 V. K. Peterson, P. D. Southon, G. J. Halder, D. J. Price, J. J. Bevitt and C. J. Kepert, Chem. Mater., 2014, 26, 47124723.

42 C. Duan, F. Li, S. Luo, J. Xiao, L. Li and H. Xi, Chem. Eng. J., 2018, 334, 1477-1483.

43 K. S. W. Sing, D. H. Everett, R. A. W. Haul, L. Moscou, R. A. Pierotti, J. Rouquerol and T. Siemieniewska, Pure Appl. Chem., 1985, 57, 603-619.

44 S. D. Worrall, M. A. Bissett, W. Hirunpinyopas, M. P. Attfield and R. A. W. Dryfe, J. Mater. Chem. C, 2016, 4, 8687-8695.
45 A. J. Bard and L. R. Faulkner, Electrochemical Methods: Fundamentals and Applications, John Wiley \& Sons, Inc, New York, 2nd edn, 2001.

46 P. Zanello, Inorganic Electrochemistry: Theory, Practice and Application, The Royal Society of Chemistry, Cambridge, UK, 2003.

47 C. Xia and W. Ning, Analyst, 2011, 136, 288-292.

48 F. Gao, L. Zhu, H. Li and H. Xie, Mater. Res. Bull., 2017, 93, 342-351.

49 R. Guidelli, R. G. Compton, J. M. Feliu, E. Gileadi, J. Lipkowski, W. Schmickler and S. Trasatti, Pure Appl. Chem., 2014, 86, 245-258.

50 J. Du, J. J. Cullen and G. R. Buettner, Biochim. Biophys. Acta, 2012, 1826, 443-457.

51 M. P. Bradshaw, C. Barril, A. C. Clark, P. D. Prenzler and G. R. Scollary, Crit. Rev. Food Sci. Nutr., 2011, 51, 479-498.

52 R. Zahn, G. Coullerez, J. Vörös and T. Zambelli, J. Mater. Chem., 2012, 22, 11073-11078.

53 N. Nasirizadeh, Z. Shekari, H. R. Zare, M. R. Shishehbore, A. R. Fakhari and H. Ahmar, Biosens. Bioelectron., 2013, 41, 608-614.

54 N. Nasirizadeh, Z. Shekari, M. Tabatabaee and M. Ghaani, J. Braz. Chem. Soc., 2015, 26, 713-722.

55 H. Sun, J. Chao, X. Zuo, S. Su, X. Liu, L. Yuwen, C. Fan and L. Wang, RSC Adv., 2014, 4, 27625-27629.

56 J. Du, R. Yue, F. Ren, Z. Yao, F. Jiang, P. Yang and Y. Du, Biosens. Bioelectron., 2014, 53, 220-224.

57 K. Ghanbari and N. Hajheidari, Anal. Biochem., 2015, 473, 53-62.

58 Y. Zhang, Y. Ji, Z. Wang, S. Liu and T. Zhang, RSC Adv., 2015, 5, 106307-106314.

59 C. Zou, J. Zhong, J. Wang, Y. Shiraishi, S. Li, B. Yan, J. Guo and Y. Du, RSC Adv., 2016, 6, 92502-92509.

60 H. Wang, L. Xiao, X. Chu, Y. Chi and X. Yang, Chin. J. Anal. Chem., 2016, 44, e1617-e1625.

61 D. Zhao, G. Yu, K. Tian and C. Xu, Biosens. Bioelectron., 2016, 82, 119-126.

62 P. L. dos Santos, V. Katic, K. C. F. Toledo and J. A. Bonacin, Sens. Actuators, B, 2018, 255, 2437-2447.

63 R. Seetharaj, P. V. Vandana, P. Arya and S. Mathew, Arabian J. Chem., 2019, 12, 295-315. 